\title{
Prediction of Starch, Moisture, and Sugar in Sweetpotato by Near Infrared Transmittance
}

\author{
Kenji Katayama, Katsumi Komaki, and Seiji Tamiya \\ Department of Crop Breeding, National Agriculture Research Center, \\ Kannondai, Tsukuba, 305 Japan
}

Additional index words. Ipomoea batatas, breeding

Abstract. Near infrared analysis was used to predict the starch, moisture, and sugar content in sliced fresh sweetpotato [Ipomoea batatas (L.) Lam.] storage roots. Samples were collected in each of three growing years. The best calibration equation for starch from combined samples (1989 to 1991) showed a multiple correlation coefficient $(R)$ of 0.949 , a standard error of calibration (SEC) of 2.01, and a standard error of prediction (SEP) of 1.91. The $R$, SEC, and SEP for moisture and sugar were $0.930,1.85$, and 2.00 , and $0.837,1.30$, and 1.21 , respectively. Calibrations based on samples from a given year adequately predicted the variables but could not account for variances introduced by samples from other years. Multiyear calibrations based on several years of data adequately predicted starch and moisture content in root slices. Thus, multiyear calibrations with annual bias adjustments can be applied to screening sweetpotato breeding germplasm for these two variables.

In Japan, the sweetpotato has many diverse uses. The important fresh market has stringent standards for many cultivars that vary greatly in sweetness, starch, and dry matter. Industrial starch producers, the alcoholic beverage industry, and food processors likewise have unique cultivar needs. Japanese sweetpotato breeding programs face many challenges meeting the varied quality demands of consumers. Fresh-market cultivar quality is most affected by the sugar and moisture content. The sugar and starch content is important in food processing, and high starch content is desired in cultivars for starch production.

Early generation lines of sweetpotatoes are tested for many years and are retained because they possess good agronomic characteristics, but they are often discarded later if analysis shows a deficiency in starch, dry matter, or sugar concentration. Traditional assay methods, particularly for starch, are too laborious to efficiently screen many progeny produced in a breeding program. Near infrared (NIR) analysis has been examined by Starr et al. (1981) and others as a way to improve the efficiency of breeding for crop quality. This technique may represent an efficient method to assay the starch, dry matter, and sugar content simultaneously in sweetpotato. However, several factors affect the accuracy of NIR predictions for a given genotype (Norris and Williams, 1984;

Received for publication 27 Sept. 1995. Accepted for publication 22 Mar. 1996. We thank D.R LaBonte, Louisiana State Univ., for critical reading of the English version of this paper and are grateful to I. Tarumoto, Osaka Prefecture Univ.; M. Otani, Ishikawa Agricultural College; and T. Tsutsumi, Japan Food Research Laboratories, for their helpful advice. The cost of publishing this paper was defrayed in part by the payment of page charges. Under postal regulations, this paper therefore must be hereby marked advertisement solely to indicate this fact.

Osborne et al., 1982; Valdes et al., 1990; Williams and Cordeiro, 1985; Williams et al., 1982). Prediction errors vary greatly due to the environment, i.e., year and location effects and the assay temperature.

NIR analysis is widely used in cereal breeding programs by measuring the reflectance spectra in ground samples. This is an efficient method for crops with inherently low moisture content. However, root crops, like sweetpotato, with $>60 \%$ moisture content cannot be prepared quickly for this assay. NIR analysis is adapted to determine the composition of intact fruit and tubers (Birth et al., 1985; Dull et al., 1989a, 1989b; Kawano et al., 1992, 1993). Although NIR analysis in sweetpotato was studied in dry, ground samples (Lu and Sheng, 1990), we found no previous work with NIR analysis in fresh sweetpotato storage roots.

Our experiments were undertaken to assess the accuracy of NIR analysis for starch, moisture, and sugar determination in fresh sweetpotato storage roots and to investigate variation in these components across growing years.

\section{Materials and Methods}

Plant materials and general procedures. Sweetpotato clones were grown in production fields at the National Agricultural Research Center, Ibaraki, Japan, in 1989, 1990, and 1991. Clones varied in starch content from $\approx 5 \%$ to $31 \%$, moisture from $\approx 53 \%$ to $80 \%$, and sugar from $\approx 6 \%$ to $19 \%$. In 1989,130 roots of 16 cultivars were used for starch prediction, and 247 roots of 10 cultivars for moisture and sugar. In 1990 and 1991, 120 roots of 12 cultivars were used for starch prediction, moisture, and sugar. Storage roots harvested in each year were stored at $15 \mathrm{C}$ and $\approx 90 \%$ relative humidity for at least 1 month without prior curing. Five to 25 storage roots for each cultivar, weighing between 200 and $300 \mathrm{~g}$ each, were randomly selected for analysis. These storage roots were washed and allowed to dry at $24 \mathrm{C}$ before analysis. Sections $5 \mathrm{~mm}$ thick were sliced vertical to the long axis from the middle third of the storage root using a handoperated meat slicer. Two slices were used to measure the NIR spectra. These slices and the remainder of the root were subsequently used to quantify starch, moisture, and sugar using standard laboratory methods. Each root was tested separately.

Starch, moisture, and sugar determination. Starch content was determined by the sedimentation method after blending $200 \mathrm{~g}$ of root tissue in $500 \mathrm{ml}$ water (Onoda, 1955). The moisture content was determined by drying 5 $\mathrm{g}$ of root tissue at $100 \mathrm{C}$ for $3 \mathrm{~h}$. Sugar content was determined using a digital refractometer (Atago Co., Tokyo) for root tissue juice centrifuged at $281,740 \times g$ for $10 \mathrm{~min}$ (see Table 1 ).

NIR estimations. A NIR spectrophotometer (model 6250; Pacific Scientific, Silver Spring, Md.) was used to measure the transmittance spectra of the slices from 680 to 1235 $\mathrm{nm}$. A slice was put on a sample holder provided with a glass disk $2 \mathrm{~cm}$ in diameter. Monochromatic light was used to illuminate the bottom of the slice on the holder, then the amount of radiation transmitted through the slice was measured by a detector located just above the slice. The standard reference was taken using an empty sample holder. The ratio of the spectrum for the slice to the spectrum for the reference is the relative transmittance $(\mathrm{T})$ spectrum for the storage root slice. The room was kept at $24 \mathrm{C}$ for NIR measurements.

Data analysis. The Near Infrared Spectral Analysis Software program (Pacific Scientific Co.) was used for statistical analysis. Two original spectra of two slices per root were averaged, and the averaged spectrum of the calibration set was converted into the second derivative spectrum with the segment size of $20 \mathrm{~nm}$ and the gap size of $0 \mathrm{~nm}$, as detailed by Kawano et al. (1992).

All sample data were separated randomly into two groups: a calibration set used to develop the calibration equations and a prediction set drawn from the same population of samples but not included in the calibration sets. Calibration equations were derived by multiple regression analysis as follows: $\mathrm{Y}(\%)$ $=\mathrm{K} 0+\mathrm{K} 1 \mathrm{~L}(\lambda 1)+\mathrm{K} 2 \mathrm{~L}(\lambda 2)+\mathrm{K} 3 \mathrm{~L}(\lambda 3)+$ $\mathrm{K} 4 \mathrm{~L}(\lambda 4)$, where $\mathrm{Y}$ is the dependent variable for starch, moisture, or sugar using standard laboratory methods; $\mathrm{K} 0$ is the regression equation intercept; $\mathrm{K} 1, \mathrm{~K} 2, \mathrm{~K} 3$, and $\mathrm{K} 4$ are regression coefficients; $\mathrm{L}(\lambda 1), \mathrm{L}(\lambda 2), \mathrm{L}(\lambda 3)$, and $\mathrm{L}(\lambda 4)$ are the independent variables for the second derivative spectra data, $\mathrm{d}^{2} \log [1 / \mathrm{T}(\lambda 1)]$, $\mathrm{d}^{2} \log [1 / \mathrm{T}(\lambda 2)], \mathrm{d}^{2} \log [1 / \mathrm{T}(\lambda 3)]$, and $\mathrm{d}^{2} \log [1 / \mathrm{T}(\lambda 4)]$; and $\lambda 1, \lambda 2, \lambda 3$, and $\lambda 4$ is the wavelength in nanometers.

Multiple linear regression analysis was used to assess the accuracy of calibration equations by means of the following terms: 1 ) the multiple correlation coefficient $(R)$ measures the strength of the linear relationship between a dependent variable and a linear combination of a set of independent variables on the calibration set; 2) the standard error of calibration 
Postharvest Biology \& Technology

Table 1. Numbers of samples, range, mean, and standard deviation of calibration and prediction sets for sweetpotato harvested in 1989, 1990 , and 1991.

\begin{tabular}{|c|c|c|c|c|c|c|c|c|c|}
\hline \multirow[b]{3}{*}{ Set } & \multicolumn{9}{|c|}{ Year } \\
\hline & \multicolumn{3}{|c|}{1989} & \multicolumn{3}{|c|}{1990} & \multicolumn{3}{|c|}{1991} \\
\hline & $\begin{array}{c}\text { No. } \\
\text { samples }\end{array}$ & $\begin{array}{c}\text { Range } \\
(\%)\end{array}$ & $\begin{array}{c}\text { Mean } \\
(\%)\end{array}$ & $\begin{array}{c}\text { No. } \\
\text { samples }\end{array}$ & $\begin{array}{c}\text { Range } \\
(\%)\end{array}$ & $\begin{array}{c}\text { Mean } \\
(\%)\end{array}$ & $\begin{array}{c}\text { No. } \\
\text { samples }\end{array}$ & $\begin{array}{c}\text { Range } \\
(\%)\end{array}$ & $\begin{array}{c}\text { Mean } \\
(\%)\end{array}$ \\
\hline \multicolumn{10}{|l|}{ Starch } \\
\hline Calibration $^{2}$ & 78 & $6.4-29.4$ & $18.4 \pm 6.0$ & 72 & $5.4-30.5$ & $19.3 \pm 6.4$ & 72 & $8.1-31.0$ & $20.2 \pm 6.4$ \\
\hline Prediction $^{y}$ & 52 & $5.1-28.1$ & $18.2 \pm 6.3$ & 48 & $7.7-29.8$ & $19.5 \pm 6.2$ & 48 & $8.5-31.0$ & $20.4 \pm 6.3$ \\
\hline \multicolumn{10}{|l|}{ Moisture } \\
\hline Calibration & 150 & $55.0-77.8$ & $64.3 \pm 4.7$ & 72 & $58.6-79.7$ & $67.1 \pm 4.8$ & 72 & $58.1-78.0$ & $67.2 \pm 5.1$ \\
\hline Prediction & 97 & $54.4-79.0$ & $64.3 \pm 5.1$ & 48 & $56.5-77.7$ & $67.0 \pm 4.7$ & 48 & $58.7-79.9$ & $67.1 \pm 5.2$ \\
\hline \multicolumn{10}{|l|}{ Sugar } \\
\hline Calibration & 150 & $6.2-18.9$ & $12.3 \pm 2.7$ & 72 & $10.2-18.6$ & $12.9 \pm 1.7$ & 72 & $8.3-16.8$ & $12.1 \pm 2.2$ \\
\hline Prediction & 97 & $6.1-17.3$ & $12.3 \pm 2.8$ & 48 & $10.4-17.7$ & $13.1 \pm 1.7$ & 48 & $8.6-15.5$ & $12.1 \pm 2.1$ \\
\hline
\end{tabular}

${ }^{\mathrm{z}}$ Calibration set is used to develop the calibration equation.

yrediction set is used to estimate the accuracy of the calibration equation, drawn from the same population of samples but not included in the calibration set.

(SEC) measures the calibration fit calculated by determining the standard deviation of the difference between the results of the standard laboratory test and the NIR-predicted value for the calibration set; 3 ) the standard error of prediction (SEP) is a measure of the performance of a calibration equation relative to the prediction set; the bias is a measure of the mean difference between the standard laboratory and NIR-predicted values relative to the prediction set; and 4) the simple correlation coefficient $(r)$ is a measure of the strength of a linear relationship between two variables (the standard laboratory and NIR-predicted values) relative to the prediction set. The paired $t$ test was used to check the difference between the NIR and standard laboratory methods, and $\mathrm{t}_{\mathrm{n}-1}$, the $\mathrm{t}$ value with $\mathrm{n}-1$ degrees of freedom, was calculated as follows: $\mathrm{t}_{\mathrm{n}-1}=\mathrm{MD} / \mathrm{SED} / \sqrt{\mathrm{n}}$ where MD is the mean difference between both values; SED is the standard error of difference between both values, and $\mathrm{n}$ is the number of samples.

The multiple-year calibration was made by combining sample data from 3 years (1989 to 1991) for comparing single-year and multiyear calibration accuracy.

\section{Results and Discussion}

Calibration and prediction. In the NIR spectra, absorption was strong at $\approx 980$ and $1150 \mathrm{~nm}$ (Fig. 1).

In the multiyear calibration, correlation coefficients at each wavelength between the second derivative data $\left[\mathrm{d}^{2} \log (1 / \mathrm{T})\right]$ and starch were significant $(P<0.05)$ and positive at 874 and $948 \mathrm{~nm}$ and negative at 765,910,997, and $1161 \mathrm{~nm}$ (Fig. 2A). For moisture, positive significant correlation coefficients existed at 910 and $999 \mathrm{~nm}$ and negative at 881 and 948 nm (Fig. 2B). For sugar, correlation coefficients were significant and positive at 732 , 833 , and $950 \mathrm{~nm}$ and negative at 914 and 1030 nm (Fig. 2C). Similar results were obtained from each of the three single-year calibrations (data not shown).

The correlation coefficients between $\mathrm{d}^{2} \log (1 / \mathrm{T})$ and chemical properties at applicable wavelengths are negative since characteristic absorption bands in the second derivative appear as negative peaks (Kawano et al., 1992). Wavelengths around 765, 910, 997, and $1161 \mathrm{~nm}$ possess a negative and high

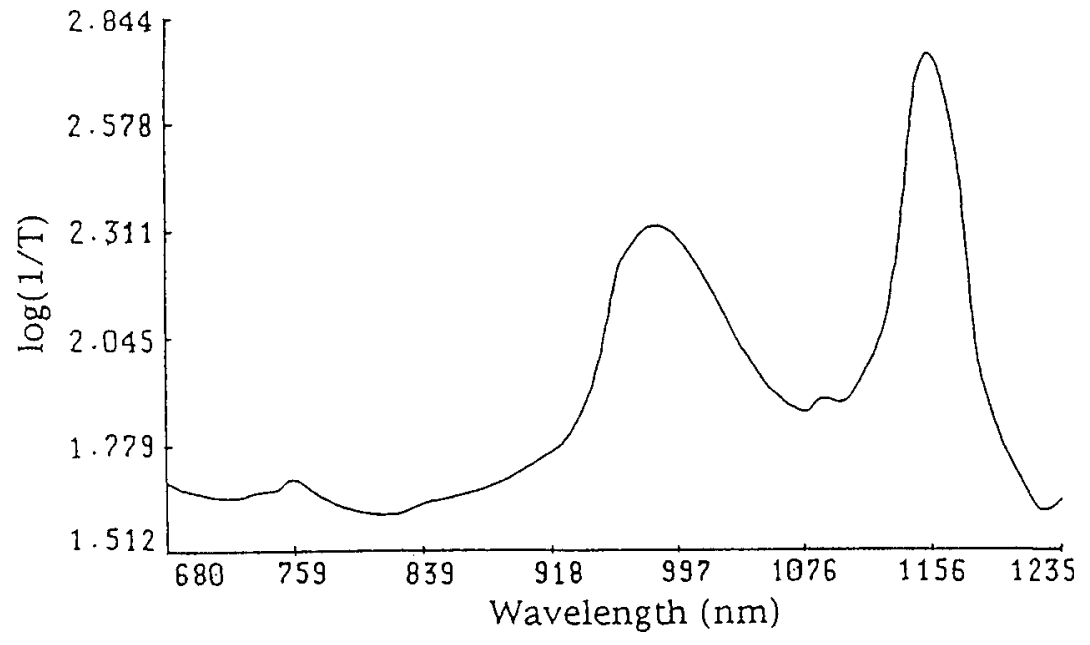

Fig. 1. Original spectra for one sweetpotato root slice $5 \mathrm{~mm}$ thick.

correlation coefficient for starch (Fig. 2A) and therefore may be associated with carbohydrates such as starch. Wavelengths around 881 and $948 \mathrm{~nm}$ possess a negative and high correlation coefficient for moisture (Fig. 2B) and therefore may be assigned to moisture. Wavelengths around 914 and $1030 \mathrm{~nm}$ possess a negative and high correlation coefficient for sugar (Fig. 2C) and therefore are assigned to sugar. Our results agree with those of Kawano et al. (1993), who selected $914 \mathrm{~nm}$ for determining sugar in satsuma mandarin (Citrus unshiu Marcovitch). Therefore, 765,910,997, and $1161 \mathrm{~nm}$ for starch; 881 and $948 \mathrm{~nm}$ for moisture; and 914 and $1030 \mathrm{~nm}$ for sugar were selected as the first wavelengths in the calibrations.

The wavelengths selected for the best calibration equations were $997,1061,834$, and $1047 \mathrm{~nm}$ for starch; 881, 1045, 980, and 758 $\mathrm{nm}$ for moisture; and 914, 881, 769, and 835 $\mathrm{nm}$ for sugar (Table 2). The following equations had the highest values for $R$ and $r$ and the lowest for SEC and SEP; the best calibration equations to predict the starch, moisture, and sugar in sweetpotato are:

$$
\begin{aligned}
\text { Starch }(\%)= & 33.28-832.50 \mathrm{~L}(997)+ \\
& 237.20 \mathrm{~L}(1061)-3596.54 \mathrm{~L}(834) \\
- & 1316.25 \mathrm{~L}(1047) \\
\text { Moisture }(\%)= & 74.76-348.71 \mathrm{~L}(881)+ \\
& 1130.24 \mathrm{~L}(1045)+ \\
& 340.24 \mathrm{~L}(980)+191.48 \mathrm{~L}(758)
\end{aligned}
$$

$$
\begin{aligned}
\text { Sugar }(\%)= & 16.92-19.86 \mathrm{~L}(914)+ \\
& 283.59 \mathrm{~L}(881)+229.57 \mathrm{~L}(769)+ \\
& 650.96 \mathrm{~L}(835)
\end{aligned}
$$

where $L(1)=d^{2} \log [1 / T(1)] ; 1$ is the wavelength.

The paired $t$ test detected no significant differences $(P \leq 0.05)$ between NIR and standard laboratory analyses for starch, moisture, and sugar measurements. The accuracy of this calibration equation for starch is acceptable for screening high-starch breeding lines. The accuracy of the calibration equation for moisture is not as high but is within an acceptable range for screening breeding materials. The accuracy of the calibration equation for sugar is lower than that for starch and moisture. Further refinements are necessary to predict sugar by NIR analysis in sweetpotato breeding programs.

Effect of growing year on accuracy of prediction. The first wavelengths $(\lambda 1)$ selected in the best multiyear calibration equation were similar for the three single-year calibrations (Table 3). No major differences among individual year calibrations existed for SEP value, bias, and $r$ for predictions within the same year. The SEP values varied $<1.83 \%$ for starch, $2.03 \%$ for moisture, and $1.19 \%$ for sugar across years. The SEP values in multiyear calibrations were slightly higher, but similar to, single-year data, although multiyear calibrations include more sample variance than single-year calibrations (Valdes et al., 1990). 

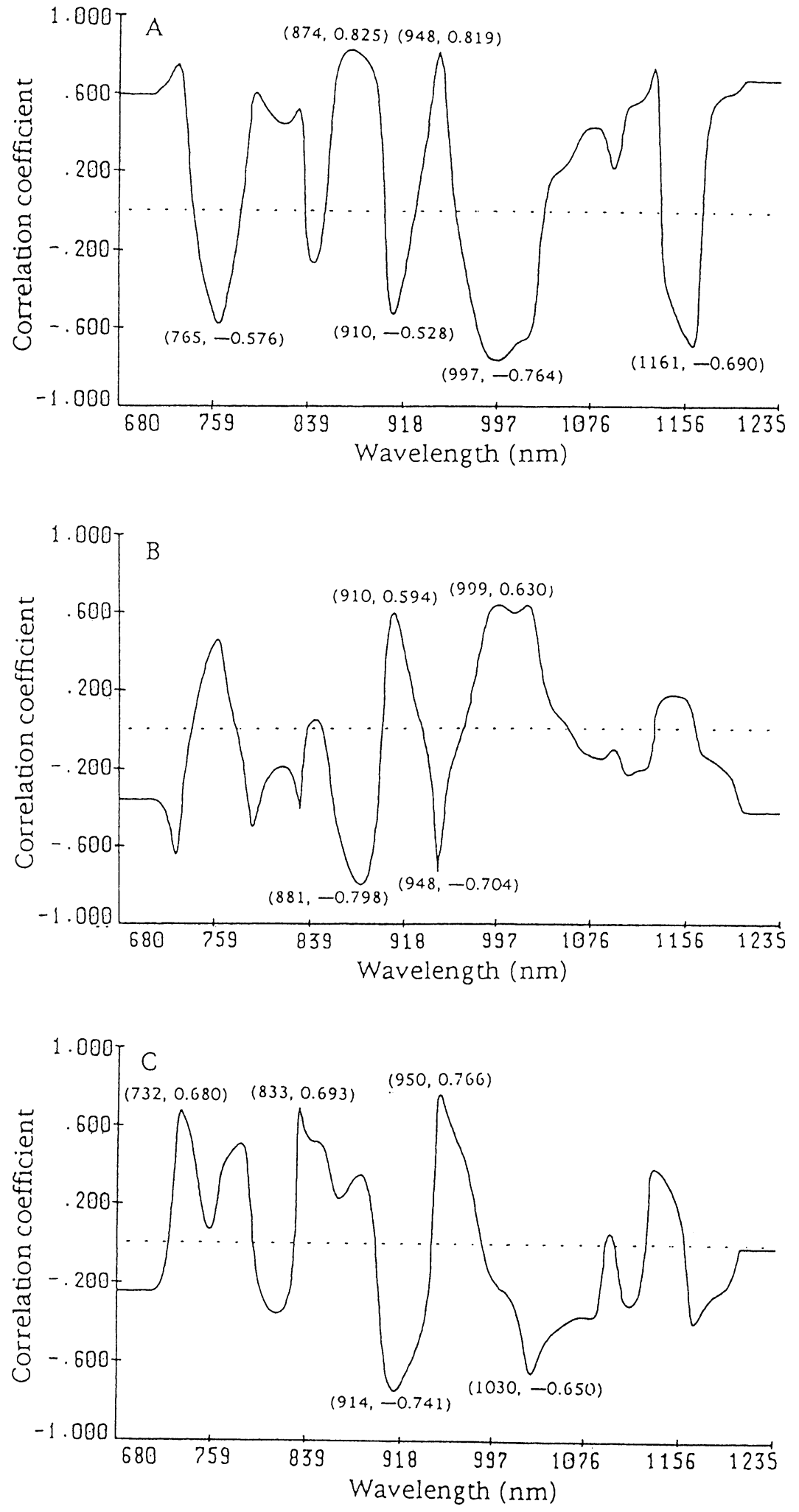

Fig. 2. Correlation coefficients between $\mathrm{d}^{2} \log (1 / \mathrm{T})$ and $(\mathbf{A})$ starch, (B) moisture, and (C) sugar plotted against wavelength.

Thus, these multiyear calibrations can be used like the single-year calibrations for predicting starch, moisture, and sugar in sweetpotato.

Single-year calibration parameters of SEP value, bias, and $r$ differed in magnitude and variability across years (Table 4). Most predictions within the same year showed lower
SEP values and biases than those in samples from other years. Thus, most calibrations based on a single growing year could not account for variances introduced by samples from other growing years. Earlier work on wheat (Triticum aestivum L.) (Williams and Cordeiro, 1985) and forage corn (Zea mays L.) (Valdes et al., 1990) suggested that annual recalibration was necessary to continue the accuracy of the predictions in samples from several years. Our results agree with this earlier work.

The multiyear calibrations for starch and moisture showed good accuracy on most predictions in all samples from the three years. The SEP value and the bias were lower for single-year calibrations than those for the predictions among several years. However, the SEP value and the bias were similar to, or slightly higher than, those for the predictions within the same year. Thus, annual bias adjustments in the multiyear calibrations are necessary to maintain accuracy. The multiyear calibration had good accuracy for predicting starch and moisture but was less accurate for predicting sugar concentration. Osborne et al. (1982) and Williams and Cordeiro (1985) reported that the multiyear (universal) calibration for wheat was highly stable and had good accuracy for predicting protein or moisture compared with single-year calibrations. Results of this study indicate that the multiyear calibrations of starch and moisture were acceptable for the screening of sweetpotato breeding materials in each year by annual bias adjustments.

\section{Literature Cited}

Birth, G.S., G.G. Dull, W.T. Renfroe, and S.J. Kays. 1985. Nondestructive spectrophotometric determination of dry matter in onions. J. Amer. Soc. Hort. Sci. 110:297-303.

Dull, G.G., G.S. Birth, and R.G. Leffler. 1989a. Use of near infrared analysis for the nondestructive measurement of dry matter in potatoes. Amer. Potato J. 66:215-225.

Dull, G.G., G.S. Birth, D.A. Smittle, and R.G. Leffler. 1989b. Near infrared analysis of soluble solids in intact cantaloupe. J. Food Sci. 54:393395.

Kawano, S., T. Fujiwara, and M. Iwamoto. 1993. Nondestructive determination of sugar content in satsuma mandarin using near infrared (NIR) transmittance. J. Jpn. Soc. Hort. Sci. 62:465470.

Kawano, S., H. Watanabe, and M. Iwamoto. 1992 Determination of sugar content in intact peaches by near infrared spectroscopy with fiber optics in interactance mode. J. Jpn. Soc. Hort. Sci. 61:445-451.

Lu, G. and J. Sheng. 1990. Application of near infrared reflectance spectroscopy (NIRS) in sweet potato quality breeding. Scientia Agricultura Sinica 23(1):76-81.

Norris, K.H. and P.C. Williams. 1984. Optimization of mathematical treatments of raw near-infrared signal in the measurement of protein in hard red spring wheat. I. Influence of particle size. Cereal Chem. 61:158-165.

Onoda. 1955. Rapid estimation of starch contents in sweet potato by the Waring blender method. J. Technol. Soc. Starch 3(2):32-38.

Osborne, B.G., S. Douglas, T. Fearn, and K.H. Willis. 1982. The development of universal calibrations for measurement of protein and moisture in UK home-grown wheat by near-infrared reflectance analysis. J. Sci. Food Agr. 33:736740.

Starr, C., A.G. Morgan, and D.B. Smith. 1981. An evaluation of near infra-red reflectance analysis in some plant breeding programmes. J. Agr. Sci., Cambridge 97:107-118. 
Table 2. Results of multiyear calibrations and predictions for starch, moisture, and sugar in sweetpotato harvested in 1989-91.

\begin{tabular}{|c|c|c|c|c|c|c|c|c|c|}
\hline \multirow[b]{2}{*}{ Component } & \multicolumn{4}{|c|}{ Wavelengths selected $(\mathrm{nm})^{\mathrm{z}}$} & \multicolumn{5}{|c|}{ Parameter $^{\mathrm{y}}$} \\
\hline & $\overline{\lambda_{1}}$ & $\lambda_{2}$ & $\lambda_{3}$ & $\overline{\lambda_{4}}$ & $R$ & SEC & SEP & Bias & $r$ \\
\hline \multirow[t]{5}{*}{ Starch } & 997 & 1061 & 834 & 1047 & 0.949 & 2.01 & 1.91 & 0.111 & 0.952 \\
\hline & 997 & 964 & 1058 & 773 & 0.946 & 2.05 & 1.92 & -1.310 & 0.952 \\
\hline & 765 & 998 & 1061 & 834 & 0.940 & 2.17 & 2.08 & -0.086 & 0.944 \\
\hline & 910 & 989 & 1061 & 854 & 0.944 & 2.08 & 2.06 & -0.007 & 0.945 \\
\hline & 1161 & 913 & 990 & 1061 & 0.933 & 2.27 & 2.12 & -0.089 & 0.941 \\
\hline \multirow[t]{3}{*}{ Moisture } & 881 & 1045 & 980 & 758 & 0.930 & 1.85 & 2.00 & 0.035 & 0.923 \\
\hline & 881 & 910 & 844 & 990 & 0.916 & 2.02 & 2.11 & 0.035 & 0.914 \\
\hline & 948 & 875 & 1055 & 835 & 0.915 & 2.03 & 2.19 & -0.043 & 0.907 \\
\hline \multirow[t]{3}{*}{ Sugar } & 914 & 881 & 769 & 835 & 0.837 & 1.30 & 1.21 & -0.135 & 0.870 \\
\hline & 914 & 980 & 767 & 832 & 0.834 & 1.31 & 1.23 & -0.193 & 0.865 \\
\hline & 1030 & 950 & 859 & 733 & 0.821 & 1.35 & 1.27 & -0.140 & 0.854 \\
\hline
\end{tabular}

${ }^{\mathrm{z}} \lambda_{1}, \lambda_{2}, \lambda_{3}, \lambda_{4}=$ the first, second, third, and fourth wavelengths in the calibration equation, respectively. ${ }^{y} R=$ the multiple correlation coefficient, $\mathrm{SEC}=$ the standard error of calibration, $\mathrm{SEP}=$ the standard error of prediction, bias $=$ the mean difference between laboratory and NIR-predicted values, $r=$ the simple correlation coefficient.

Table 3. Calibration and prediction measurements for starch, moisture, and sugar in single-year and multiyear samples using near infrared analysis.

\begin{tabular}{|c|c|c|c|c|c|c|c|c|c|c|}
\hline \multirow[b]{2}{*}{ Component } & \multirow[b]{2}{*}{ Year } & \multicolumn{4}{|c|}{ Wavelengths selected $(\mathrm{nm})^{\mathrm{z}}$} & \multicolumn{5}{|c|}{ Parameter $^{\mathrm{y}}$} \\
\hline & & $\lambda_{1}$ & $\lambda_{2}$ & $\lambda_{3}$ & $\lambda_{4}$ & $R$ & SEC & SEP & Bias & $r$ \\
\hline \multirow[t]{4}{*}{ Starch } & 1989 & 999 & 1061 & 834 & 940 & 0.956 & 1.81 & 1.64 & -0.189 & 0.965 \\
\hline & 1990 & 995 & 939 & 1057 & 832 & 0.971 & 1.57 & 1.57 & -0.079 & 0.968 \\
\hline & 1991 & 998 & 1060 & 831 & 1050 & 0.947 & 2.11 & 1.83 & 0.373 & 0.957 \\
\hline & Multi & 997 & 1061 & 834 & 1047 & 0.949 & 2.01 & 1.91 & 0.111 & 0.952 \\
\hline \multirow[t]{4}{*}{ Moisture } & 1989 & 882 & 1053 & 942 & 808 & 0.933 & 1.71 & 1.86 & -0.886 & 0.932 \\
\hline & 1990 & 872 & 1057 & 987 & 1200 & 0.956 & 1.40 & 1.74 & 0.226 & 0.930 \\
\hline & 1991 & 883 & 911 & 993 & 1058 & 0.946 & 1.71 & 2.03 & 0.020 & 0.920 \\
\hline & Multi & 881 & 1045 & 980 & 758 & 0.930 & 1.85 & 2.00 & 0.035 & 0.923 \\
\hline \multirow[t]{4}{*}{ Sugar } & 1989 & 913 & 884 & 727 & 847 & 0.877 & 1.30 & 1.19 & -0.177 & 0.907 \\
\hline & 1990 & 917 & 884 & 763 & 833 & 0.747 & 1.13 & 1.11 & -0.294 & 0.766 \\
\hline & 1991 & 911 & 882 & 769 & 832 & 0.864 & 1.15 & 0.96 & -0.021 & 0.894 \\
\hline & Multi & 914 & 881 & 769 & 835 & 0.837 & 1.30 & 1.21 & -0.135 & 0.870 \\
\hline
\end{tabular}

${ }^{2} \lambda_{1}, \lambda_{2}, \lambda_{3}, \lambda_{4}=$ the first, second, third, and fourth wavelength in calibration equation, respectively.

${ }^{y} R=$ the multiple correlation coefficient, $\mathrm{SEC}=$ the standard error of calibration, $\mathrm{SEP}=$ the standard error of prediction, bias $=$ the mean difference between laboratory and NIR-predicted values, $r=$ the simple correlation coefficient.

Table 4. Effect of year on the accuracy of near infrared predictions for starch, moisture, and sugar in sweetpotato.

\begin{tabular}{|c|c|c|c|c|c|c|c|c|c|}
\hline \multirow{2}{*}{$\begin{array}{l}\text { Year of } \\
\text { sampling }\end{array}$} & \multicolumn{3}{|c|}{ Starch } & \multicolumn{3}{|c|}{ Moisture } & \multicolumn{3}{|c|}{ Sugar } \\
\hline & $\mathrm{SEP}^{\mathrm{Z}}$ & Bias $^{y}$ & $r^{x}$ & SEP & Bias & $r$ & SEP & Bias & $r$ \\
\hline \multicolumn{10}{|c|}{ Calibration 1989} \\
\hline 1989 & 1.64 & -0.19 & 0.965 & 1.86 & -0.89 & 0.932 & 1.19 & -0.18 & 0.907 \\
\hline 1990 & 1.60 & 2.12 & 0.966 & 2.17 & -1.53 & 0.889 & 1.10 & -1.22 & 0.770 \\
\hline 1991 & 2.21 & 2.14 & 0.936 & 2.06 & -0.85 & 0.918 & 1.15 & 0.60 & 0.842 \\
\hline \multicolumn{10}{|c|}{ Calibration 1990} \\
\hline 1989 & 1.99 & -2.68 & 0.949 & 2.85 & 2.99 & 0.830 & 1.66 & -0.66 & 0.810 \\
\hline 1990 & 1.57 & -0.08 & 0.968 & 1.74 & 0.23 & 0.930 & 1.11 & -0.29 & 0.766 \\
\hline 1991 & 2.21 & -0.70 & 0.936 & 1.84 & 0.58 & 0.935 & 1.13 & -0.08 & 0.847 \\
\hline \multicolumn{10}{|c|}{ Calibration 1991} \\
\hline 1989 & 1.95 & -2.00 & 0.951 & 2.52 & 2.12 & 0.871 & 1.32 & -1.00 & 0.884 \\
\hline 1990 & 2.18 & -0.21 & 0.937 & 2.16 & -0.68 & 0.890 & 1.07 & -1.22 & 0.785 \\
\hline 1991 & 1.83 & 0.37 & 0.957 & 2.03 & 0.02 & 0.920 & 0.96 & -0.02 & 0.894 \\
\hline \multicolumn{10}{|c|}{ Multiyear calibration (1989-91) } \\
\hline 1989 & 1.68 & -0.76 & 0.963 & 1.89 & 0.35 & 0.929 & 1.29 & -0.19 & 0.890 \\
\hline 1990 & 1.66 & 0.75 & 0.964 & 2.01 & -0.43 & 0.905 & 1.09 & -0.51 & 0.777 \\
\hline 1991 & 1.99 & 0.41 & 0.949 & 1.93 & -0.14 & 0.928 & 0.95 & 0.35 & 0.895 \\
\hline
\end{tabular}

${ }^{\mathrm{z}} \mathrm{SEP}=$ the standard error of prediction.

${ }^{\mathrm{y}} \mathrm{Bias}=$ the mean difference between laboratory and NIR-predicted values.

${ }^{\mathrm{x}} r=$ the simple correlation coefficient.
Valdes, E.V., G.E. Jones, and G.J. Hoekstra. 1990. Effect of growing year and application of a multi-year calibration for predicting quality parameters by near infrared reflectance spectroscopy in whole-plant corn forage. Can. J. Plant Sci. 70:747-755.

Williams, P.C. and H.M. Cordeiro. 1985. Effect of calibration practice on correction of errors induced in near-infrared protein testing of hard red spring wheat by growing location and season. $\mathrm{J}$. Agr. Sci., Cambridge 104:113-123.

Williams, P.C., K.H. Norris, and W.S. Zarowski. 1982. Influence of temperature on estimation of protein and moisture in wheat by near-infrared reflectance. Cereal Chem. 59:473-477. 